\title{
PRIVATIZAÇÃO DA EDUCAÇÃO INFANTIL EM CAMPINAS E SUAS IMPLICAÇÕES NO ATENDIMENTO ÀS CRIANÇAS PEQUENAS E PEQUENININHAS EM CRECHES E PRÉ-ESCOLAS CAMPINEIRAS ${ }^{*}$
}

Nélia Ap. da Silva Cavalcante

\section{Introdução}

A Educação Infantil, primeira etapa da Educação Básica no Brasil, sempre ocupou um papel secundário nas políticas públicas para a educação nacional. Com a Constituição Federal de 1988, passa a ser determinado como direito das crianças pequenas e pequenininhas e de suas famílias o atendimento em creches e pré-escolas públicas, bem como delimita o atendimento à demanda aos municípios. Ora, estabelecer um direito não garante sua efetivação na prática, porém, há mecanismos legais que obrigam os governantes a cumprirem o que dita a lei, mas as formas encontradas por estes nem sempre são as mais eficientes. Este capítulo tem por objetivo apresentar os resultados da pesquisa de mestrado Educação infantil e as relações público-privado no município de Campinas: o Programa Naves-Mãe, defendida por Silva (2016), cujo intuito foi discutir a resposta que o município de Campinas apresentou ao Ministério Público em 2005, quando cobrado pelo déficit de mais de quinze mil vagas nas creches e pré-escolas campineiras: o Programa Naves-Mãe, uma iniciativa de privatização da Educação Infantil no município, a partir de parcerias público-privadas. Para tanto, contará com três seções: a primeira, em que será apresentada a composição da Educação Infantil em Campinas; a segunda seção apresenta a organização e os princípios que regem o Programa Naves-Mãe Campinas e o processo de parcerias público-privado e, por fim, na terceira seção serão apresentadas as implicações que este programa traz para a educação das crianças nas creches e pré-escolas, bem como para a garantia de seus direitos.

${ }^{*}$ DOI - 10.29388/978-65-86678-02-4-0-f.169-184 


\section{A Educação Infantil em Campinas}

A Educação Infantil, de acordo com a Constituição Federal de 1988 e a Lei de Diretrizes e Bases da Educação Nacional (LDB) de 1996, constitui a primeira etapa da Educação Básica, devendo ser ofertada exclusivamente pelos munícipios.

Art. 29. A educação infantil, primeira etapa da educação básica, tem como finalidade o desenvolvimento integral da criança até seis anos de idade, em seus aspectos físico, psicológico, intelectual e social, complementando a ação da família e da comunida de.

Art. 30. A educação infantil será oferecida em:

I - creches, ou entidades equivalentes, para crianças de até três anos de idade;

II - pré-escolas, para as crianças de quatro a cinco anos e 11 meses de idade.

[...]

Art. 211. A União, os Estados, o Distrito Federal e os Municípios organizarão em regime de colaboração seus sistemas de ensino.

$\S 1$ o A União organizará o sistema federal de ensino e o dos Territórios, financiará as instituições de ensino públicas federais e exercerá, em matéria educacional, função redistributiva e supletiva, de forma a garantir equalização de oportunidades educacionais e padrão mínimo de qualidade do ensino mediante assistência técnica e financeira aos Estados, ao Distrito Federal e aos Municípios.

$\$ 2$ o Os Municípios atuarão prioritariamente no ensino fundamental e na educação infantil. [...] (BRASIL, 1996, p. 38)

De acordo com Rosemberg (2002), em virtude das leis, os municípios precisaram organizar o atendimento às crianças da Educação Infantil da cidade, buscando alternativas para cumprir a obrigatoriedade que as legislações impõem. Para isso, criaram, nas décadas de 1970 a 1990, diferentes políticas na América Latina e no Brasil, emba- 
sadas em orientações dos organismos multilaterais, em especial o Banco Mundial (BM) e o Fundo das Nações Unidas para a Infância (UNICEF). Políticas estas que se pautavam em fazer "mais por menos", ou seja, atendimento precário e de baixos investimentos, que partiam dos seguintes princípios:

- a expansão da EI constitui uma via para combater a pobreza (especialmente desnutrição) no mundo subdesenvolvido e melhorar o desempenho do ensino fundamental, portanto, sua cobertura deve crescer;

- os países pobres não dispõem de recursos públicos para expandir, simultaneamente, o ensino fundamental (prioridade número um) e a EI;

- a forma de expandir a EI nos países subdesenvolvidos é por meio de modelos que minimizem investimentos públicos, dada a prioridade de universalização do ensino fundamental;

- para reduzir os investimentos públicos, os programas devem se apoiar nos recursos da comunidade, criando programas denominados "não formais", "alternativos", "não institucionais", isto é, espaços, materiais, equipamentos e recursos humanos disponíveis na "comunidade", mesmo quando não tenham sido concebidos ou preparados para essa faixa etária e para seus objetivos. (ROSEMBERG, 2002, p. 34)

Em seus estudos, a autora aponta que para a Educação Infantil as políticas públicas sempre foram precárias, de baixa qualidade e feitas de formas quaisquer, objetivando atender à demanda, independente das implicações que um atendimento precário traz para a garantia dos direitos das crianças e de suas famílias, como preconiza a Constituição Federal.

Em Campinas, cidade-alvo deste estudo, a Educação Infantil sempre esteve na pauta das politicas públicas educacionais do município. Ela nasce nos anos de 1914, de acordo com Tonolli (1996), da assistência e da busca por higienização das crianças em situação de vulnerabilidade, mas vai se consolidando ao longo dos anos como expe- 
riências progressistas, como os Parques e Recantos Infantis nas décadas de 1940 a 1960, até se constituir como a primeira cidade brasileira a atender o que a Constituição Federal legislou, tirando a creche da assistência e colocando na pasta da Educação.

Em relação à construção de um currículo para esta etapa da educação, a Secretaria Municipal de Educação (SME), na década de 1990, elabora, em parceria com os/as educadores/as, o Currículo em Construção, documento que por quase três décadas norteará o trabalho dessa etapa da Educação no município, até a elaboração das Diretrizes Curriculares Municipais para a Educação Infantil, em 2013. O documento Currículo em Construção se configura como um documento importante da rede, pois foi construído de forma democrática por todos os profissionais que atendiam às crianças nas unidades, bem como os especialistas da Secretaria, sempre de forma transparente, colaborativa e baseando-se na realidade e no contexto da educação da cidade. As Diretrizes contaram, em sua elaboração, com trocas entre os pares, porém, o alcance e a lisura desse movimento não foram os mesmos do Currículo.

Campinas, ao longo dos anos, buscou construir uma rede própria de atendimento à Educação Infantil, ao Ensino Fundamental e à Educação de jovens e adultos; porém, para a primeira etapa da educação, a exemplo do que foi preconizado por Rosemberg (2002), também aderiu a formas alternativas para atender à demanda por creches e pré-escolas para a população.

Neste sentido, sempre estabeleceu parcerias com entidades assistenciais, a maioria ligada à Fundação das Entidades Assistenciais de Campinas (FEAC), na complementação ao atendimento nas unidades públicas, ofertando fomento às instituições para atenderem às crianças pequenas e pequenininhas.

Paralelo a esses fatos, a cidade foi construindo sua rede de Educação Infantil, que contava, em 2016, de acordo com o Diagnóstico Plano Municipal de Educação, de março de 2015, com cento e cinquenta e cinco unidades públicas de Educação Infantil, atendendo à população de 0 a 3 anos, e quarenta e cinco unidades atendendo à pré- 
escola $^{1}$ (deste total, vinte e duas são destinadas ao Programa NavesMãe), além de trinta e nove unidades conveniadas atendendo em parceria com a SME. No momento da escrita deste texto, fevereiro de 2020, o número de unidades do Programa Naves-Mãe no município aumentou, bem como as unidades conveniadas, em detrimento de nenhuma inauguração de unidades de Educação Infantil públicas. O prefeito Jonas Donizetti (PSB) anunciou no final de 2019 a implementação de vouchers de R \$1000,00 para os pais matricularem seus filhos/ suas filhas em unidades de Educação Infantil particular da cidade, a fim de atender à demanda por vagas.

Como pode ser deduzido pelo que foi apresentado acima, a cidade de Campinas, uma das mais ricas do estado de São Paulo, que já foi referência em inovação no atendimento à Educação Infantil, caminha a passos largos para a privatização do serviço, por meio de parcerias público-privados que visam à entrega de unidades públicas para a cogestão por Organizações Sociais (OSs). Na próxima seção, discutirse-á o Programa Naves-Mãe e sua constituição.

\section{Privatização da Educação Infantil: o Programa Naves-Mãe}

Como já foi mencionado, Campinas sempre teve uma preocupação com a oferta de uma Educação Infantil que atendese ao direito das crianças pequenas e pequeninas e suas famílias para frequentarem as creches e pré-escolas municipais. Buscou e busca ofertar formação continuada aos docentes e às(aos) monitoras(es), por intermédio do Centro de Formação, Tecnologia e Pesquisa Milton Santos (CEFORTEPE). Porém, as formas utilizadas pelas gestões públicas nem sempre privilegiaram apenas o atendimento público, como também já foi explicitado. Para este capítulo, será apresentada uma das formas de parceria da SME com as organizações sociais, a fim de atender à demanda de vagas no munícipio, o Programa Naves-Mãe.

\footnotetext{
${ }^{1}$ Os números referem-se à Educação Infantil nas EMEIs, CEMEIs e Naves-Mãe, consideradas pela SME como públicas.
} 
A Reforma do Estado, preconizada no Plano Diretor da Refor ma do Aparelho do Estado (PDRAE), e implementada no Estado brasileiro no ano de 1995, apresentou novas formas gerencialistas de administração públicas contendo maneiras de atendimento, pela sociedade civil, de serviços que estavam destinados apenas às esferas públicas, dentre eles a gestão dos equipamentos públicos em parceria com o setor privado.

Nesse contexto, as prefeituras, os estados e a União ficaram autorizados a estabelecer parcerias com a sociedade civil, para atender às demandas que surgissem em suas instâncias e para suprir as necessidades da população, não onerando os cofres públicos, cujo teto dos gastos passou a ser limitado pela Lei de Responsabilidade Fiscal, Lei Complementar no 101 de 04 de maio de 2000. Com o PDRAE, os municípios estabeleceram parcerias diversas para o atendimento à demanda de vagas, em um processo denominado publicização.

Neste sentido, a escolha pela oferta de serviços por uma instituição pública não estatal implica que os serviços essenciais podem ser gerenciados pelo privado, mas não podem ser totalmente desvinculados do Estado, uma vez que este é seu principal subsidiador. Em outras palavras, estes não podem ser totalmente repassados para as empresas privadas, que visam apenas o lucro, mas atesta que para poder alcançar a universalização da demanda é necessário que se façam parcerias com o setor privado, dentro de uma administração gerencial, que possibilite certo controle do Estado. (SILVA, 2016, p. 112)

Nesse contexto, segundo Peroni (2010), tais ações implicariam uma definição de quase-mercado, uma vez que a lógica mercadológica passa a ser aplicada às políticas de Estado, ainda que este não se isente do financiamento dos serviços, mas o gerenciamento passa a ser executado pela sociedade civil, dentro da lógica de gestão do mercado.

Dentro dessa lógica são estabelecidas diversas parcerias e convênios, que, segundo os apontamentos nos estudos de Adrião, 
Borghi e Domiciano (2010), bem como Oliveira e Borghi (2013), vão desde a subvenção de recursos públicos para matrículas em escola privadas, concessão de recursos físicos, materiais entre outros para a gestão em parceria com ONGs até compras de materiais apostilados e sistemas de gestão por empresas educacionais. Infelizmente, os recursos que deveriam ser usados apenas com entidades sem fins lucrativos têm outros rumos, pois "[...] a simbiose entre os setores público e privado para a oferta da educação infantil atua para ampliar espaços de atuação e lucro do setor privado com fins lucrativos" (DOMICIANO, FRANCO; ADRIÃO, 2011, p. 316). Por fim, as autoras colocam que qualquer forma de parceria é perigosa e não poderia ocorrer, pois o dinheiro público deveria ser usado apenas em instituições públicas. (SILVA, 2016, p. 121-122)

Em Campinas, o Programa Naves-Mãe se configura em uma política de privatização, em que o órgão público constrói e equipa as unidades e as entrega para a cogestão por Organizações Sociais, em uma parceria que teoricamente não onera os cofres públicos em relação à garantia da Lei de Responsabilidade Fiscal. Mas traz sérias implicações em relação à garantia dos direitos à oferta de uma educação pública laica, gratuita e de qualidade às crianças pequenas e pequeninas campineiras.

Esse Programa nasce da necessidade que a SME, em 2005, tinha de suprir a demanda por mais de 15000 vagas em creches e préescolas, em determinação do Ministério Público, que acatou a denúncia da Vara da Infância e Juventude, sob pena de pagamento de multa diária a partir de 2009.

De acordo com Silva (2016), para solucionar esse problema, a prefeitura engendrou uma série de ações: a criação do Programa Especial de Ampliação da Oferta na Educação Infantil (Pró-Criança), que tinha como objetivo a garantia de vagas às crianças da Educação Infantil no município; a Lei 12884/2007, que cria o Programa de Atendimento Especial à Educação Infantil (PAEEI), que permite a criação de Centros de Educação Infantil cogestados pela sociedade civil e buscou 
atender, em 2007, a Lei no 11.274, que regulamenta o Ensino Fundamental de 9 anos, gerando vagas na pré-escola, uma vez que as crianças de 5 anos el1 meses ascendem ao Ensino Fundamental.

Com esses programas foram criadas 7500 vagas com a construção de 8 CEMEIs e 1 EMEI. A SME estabeleceu também parceria com 39 entidades que passaram a atender 5220 crianças, totalizando 9596 vagas preenchidas em 2011. Porém, para que esse número de vagas fosse alcançado, a secretaria passou para o Ensino fundamental 1000 crianças de 6 anos, adotando a política do Ensino de 9 anos no município a partir de 2007. (SILVA, 2016, p. 50)

As Naves-Mãe são equipamentos públicos, construídos por estruturas pré-moldadas pela SME, em parceria com o governo federal, através do Programa de Aceleração do Crescimento (PAC) e com a sociedade civil, caso de uma das unidades. São espaços planejados para atender às crianças pequenas em todas as suas especificidades, contando com setor administrativo, berçários e solários para as crianças menores; salas de aula para as crianças maiores; cozinha; refeitório; pátio comum; parques; casa de bonecas, dentre outros equipamentos necessários ao atendimento educacional das crianças.

Foto 1: vista aérea da nave, fotografada de um painel exposto no Paço Municipal, março de 2015. (SILVA, 2016, p. 49)

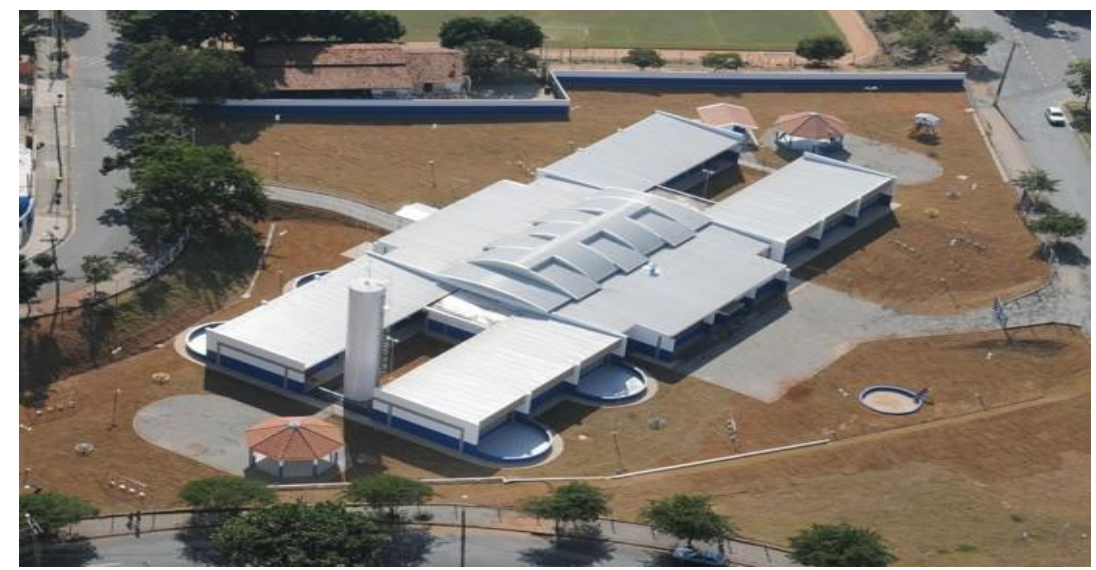


A unidade é equipada com mobiliários para todos os espaços, utensílios para uso nos diferentes setores de cozinha e limpeza, uniformes para as crianças, brinquedos para os parques e casinha de boneca, bem como toda a manutenção é realizada pelos departamentos da Prefeitura Municipal de Campinas, pois constitui unidade pública. A cargo da cogestora estão os seguintes itens: a compra de brinquedos pedagógicos para as turmas; materiais pedagógicos de uso cotidiano; pagamento de estudos do meio; contratação e pagamento de todas as funcionárias e funcionários que atendem na unidade, que deve seguir o mesmo módulo da rede. O sistema de matrícula e o acompanhamento pedagógico dos trabalhos são os mesmos da rede, sendo que cada unidade conta com a supervisão e o acompanhamento de uma supervisora ou um supervisor educacional.

Embora as Naves tenham nascido da concepção pedagógica da Pedagogia dos sentidos, que tem como norte as questões da Neurociência de construção de sinapses de aprendizagem, o currículo a ser seguido é o mesmo da rede, garantido pelas Diretrizes Curriculares Municipais de Educação Infantil (2013), que veio substituir o Currículo em Construção, como já apresentado.

Em 2016, havia no município vinte e dois equipamentos, atendendo às crianças da creche (período integral) e a pré-escola (período parcial). Destes equipamentos, vinte eram cogestados por organizações sociais de cunho religioso das mais diferentes denominações (Católicas, Nazarenas, Batistas, Presbiterianas, dentre outras), e duas por uma entidade que não tem a religiosidade como meta de construção educacional. Tal fato implica seriamente no trabalho a ser realizado com as crianças, a partir do princípio constitucional da laicidade, o que fere o estado laico.

Partindo da simples constatação, vemos que os CEIs NavesMãe parecem atender o déficit de vagas na educação infantil, haja vista o aumento significativo de vagas para as crianças de 0 a 6 anos, de 2005 até 2011. O número de matriculados aumentou significativamente e, com isso, a lista de espera diminuiu grandemente: enquanto em 2005 mais de 15 mil crianças aguar- 
davam vagas nas escolas, com o passar dos anos de implementação das Naves, o número foi caindo expressivamente até quase pela metade, atestando, em termos numéricos, o êxito do projeto. (SILVA, 2016, p.51)

Por fim, a escolha inicial da construção das unidades, que possuem capacidade de atenderem até quinhentas e trinta crianças, deuse por locais de alta vulnerabilidade social, em bolsões populacionais constituídos por ocupações da cidade, em que o número de crianças para serem atendidas era grande e nenhum equipamento público existia para suprir a demanda. Neste sentido, as vinte e duas unidades es tão distribuídas em quatro dos cinco Núcleos Descentralizados de Educação (NAEDs) existentes em Campinas: Norte, Sudoeste, Sul e Noroeste. A exceção é o NAED Leste, constituído pelos bairros "nobres” da cidade, que são atendidos por unidades próprias do município.

\section{Implicações do processo de privatização na qualidade do atendimento à demanda na Educação Infantil em Campinas}

Apresentado o Programa Naves-Mãe e as políticas que o abalizam, cabe discorrer acerca das implicações que esta política pública municipal traz para o atendimento às crianças pequenas campineiras, bem como a garantia de seus direitos a uma educação pública, gratuita, laica e de qualidade. Durante a pesquisa de Mestrado, cujo tema era referente a esse Programa, foi possível verificar diversos fatores que contribuíram para discutir a questão da qualidade no atendimento e a garantia dos direitos das crianças pequenas e pequeninhas e de suas famílias.

A primeira questão se refere à localização dos equipamentos e a concepção desses espaços como locais de fomentação de saberes para as crianças que em casa não teriam, como preconizam os estudos de Santos (2010), bem como o caráter assistencialista do programa, ao ofertar cursos profissionalizantes para as mães. 
Outro fato que chama a atenção nos sites pesquisados é o caráter assistencial que o trabalho ofertado pelas entidades aponta. Em todos eles figura-se uma preocupação com as crianças em vulnerabilidade social e econômica. Destaca-se o anúncio/oferta de matrículas para as crianças e auxílio às famílias (sobretudo às mães) em todas as unidades educacionais. Exemplificando: há ofertas para exercer função remunerada no CEI, assim como obter qualificação profissional através do acesso a determinados cursos como panificação, manicure e cabeleireiro, entre outros. Estamos às voltas do caráter assistencialista que sempre permeou as instituições de educação infantil na história. Um legado que as conquistas democráticas, como a Constituição Nacional buscou suprimir ao retirar as creches da Secretaria de Assistência, repassando para a pasta da Educação. (SILVA, 2016, p. 59)

A partir do relatado acima, as unidades dão a entender que po dem ser constituir como locais de "salvação" das crianças e de suas famílias, devido às concepções dos valores cristãos de suas entidades mantenedoras, que podem trazer um caráter evangelizador para a Educação Infantil por elas ministradas, ferindo o caráter constitucional do estado laico da educação.

A questão da laicidade, já citada, é uma preocupação em relação a essa oferta educativa, pois como os estudos apontaram, as vinte unidades religiosas cogestoras pautam seus princípios pela construção de valores morais e cristãos na construção do ser humano. Ter supervisoras para orientar, acompanhar e supervisionar o trabalho das unidades não garante que este siga o que está descrito na legislação municipal.

Os espaços físicos das instituições carecem de vegetação e de árvores que produzam sombras para as crianças poderem brincar ao ar livre. A solução encontrada pelas unidades foi transformar o pátio interno em parque, com brinquedos de plásticos que as crianças compartilham em turnos curtos sem contato com a terra, a água, a grama, o ar livre, tão importantes para essa fase da vida humana, transformando a unidade em um confinamento, em que as crianças se movem 
em turnos do brincar, não permitindo a interatividade entre as turmas, dada a precariedade do espaço.

Apesar da gravidade das questões apontadas, o que mais impactou na pesquisa foram as questões trabalhistas e de condições de trabalho, que destoam alarmantemente das condições das/dos trabalhadoras/es da rede pública direta.

A primeira questão é a diferença salarial. As professoras, monitoras, diretoras, vice-diretoras e coordenadoras pedagógicas (não há homens nesses cargos nas unidades, apenas zeladores, vigilantes e cargos administrativos) recebem cerca de um quarto do salário dos profissionais da rede, por 44 horas-relógio de trabalhos semanais, sendo que na rede professores/as têm carga horária de 24/32 h/a; monitores 30 horas-relógio e especialistas 36 horas semanais. Ou seja, as profissionais das entidades trabalham muito mais do que as/os da rede e ganham muito menos, o que compromete a qualidade do trabalho pedagógico a ser realizado com as crianças.

A segunda questão refere-se à formação continuada, que na rede ocorre nos Centros de Formação, remunerada para professores/as e descontada em horas por especialistas; e nas unidades do Programa Naves-Mãe acontecem fora do horário de trabalho das profissionais, sem remuneração. Em uma das unidades pesquisadas, o Tempo de Trabalho Docente (TDC), que por lei se constitui por $2 \mathrm{~h} / \mathrm{a}$ semanais, e o tempo de formação da entidade de $2 \mathrm{~h} / \mathrm{a}$, ocorria no horário de almo ço das funcionárias, que precisavam comer em $10 \mathrm{~min}$, ter $50 \mathrm{~min}$ de formação e no seu término assumir turma, quatro dias na semana, passando praticamente de uma turma a outra sem um tempo de descanso entre os turnos de trabalho. O que levou uma supervisora entrevistada a comparar o trabalho nas Naves à rotina cravada de uma fábrica e não a um processo educacional.

Estas são questões preocupantes, porque por mais que as profissionais sejam engajadas, busquem trazer atividades atrativas às crianças e que estejam dentro de uma proposta de uma Educação Infantil transformadora, produtora de culturas, as condições dadas limitam a prática diária, que acaba ficando fragmentada, truncada, pautada mais 
no relógio do que na construção das diferentes linguagens, com uma proposta pedagógica realmente transformadora, instigante. E isto implica diretamente na qualidade da educação ofertada que, neste sentido, não pode ser classificada como de qualidade, laica, gratuita (as unidades são públicas, mas a gestão é privada) e nem cidadã, se não se tem o princípio laico que garante o respeito à diversidade religiosa, cultural, plural das crianças.

Assim, o trabalho de campo que realizei nesta pesquisa, associado a uma discussão teórica circunstanciada sobre as políticas públicas para a educação infantil, permite afirmar que os direitos das crianças pequenas e sua família a uma educação pública gratuita, laica e de qualidade não está sendo respeitado no Brasil e menos ainda em Campinas, com a implementação de parcerias público-privado em que o interesse central reside em responder ao Ministério Público, quaisquer que sejam a condições impostas. (SILVA, 2016, p. 171)

\section{Considerações finais}

Ao finalizar este texto, em que se apresentam os resultados da pesquisa de mestrado Educação infantil e as relações público-privado no município de Campinas: o Programa Naves-Mãe, defendida em julho de 2016, na Faculdade de Educação da Unicamp, percebe-se o quanto esse programa de privatização contribui para a pauperização da Educação Infantil no município, bem como essa política veio para ficar, sendo o norte que os prefeitos, passado e atual, encontraram para privatizar a educação na cidade.

O programa expressa uma despreocupação da gestão municipal com a qualidade da educação ofertada aos pequenos e às pequenas munícipes e suas famílias, focando mais na garantia do atendimento à demanda, em detrimento da qualidade do serviço oferecido, refletindo uma tendência atual nas diferentes instâncias governamentais brasileiras e quiçá mundiais. 
A lógica mercadológica presente nessas políticas reduz o atendimento a números, sem observar as demais implicações de uma política que busca fazer "mais por menos", que traz para os processos educativos e para a formação integral das crianças.

As perspectivas de mudanças a curto e médio prazo não despontam no horizonte, sendo necessária uma real mobilização da sociedade civil pela cobrança da construção da qualidade da escola pública. Sem mobilização, não teremos mudanças, e sem mudanças logo não haverá mais educação pública, gratuita, laica e de qualidade.

\section{Referências}

BRASIL. Constituição Federativa Nacional. Brasília: MEC, 1988.

Lei de Diretrizes e Bases da Educação Nacional. Brasília:

MEC, 1996/2011

. Plano Diretor da Reforma do Aparelho do Estado. Câmara da Reforma do Estado. Brasília, 1995.

CAMPINAS. Currículo em Construção. Campinas, SP: Secretaria Municipal de Educação, 1991.

Diagnóstico Plano Municipal de Educação. Campinas, SP: Secretaria Municipal de Educação, março de 2015.

CASSAN, Elaine Regina. A política de educação infantil no município de Campinas-SP: um diálogo com as fontes documentais. Faculdade de Educação, Campinas, 2013.Tese de doutorado/ FE Unicamp. Campinas, SP, 2013.

PERONI, Vera Maria Vidal. A democratização da educação em tempos de parcerias entre o público e o privado. Revista Educação Pública, Cuiabá, v. 19 n. 40 p. 215-227 maio/ago. 2010.

ROSEMBERG, Fúlvia. Organizações multilaterais, estado e políticas de educação infantil. Cadernos de pesquisa, $\mathrm{n}^{\circ} 107$. Fundação Carlos Chagas. São Paulo, p. 25-63, março/2002. 
SANTOS, Hélio de O. Naves-Mãe e a Pedagogia dos Sentidos: de Campinas, novos paradigmas para a educação infantil no Brasil. Campinas: Komedi, 2010.

SILVA, Nélia Aparecida da. Educação infantil e as relações públicoprivado no município de Campinas: o Programa Naves-Mãe. Dissertação (Mestrado em Educação), Faculdade de Educação, Unicamp. Campinas, SP, 2016.

TONOLLI, Maria Fernanda S. As origens da educação pré-escolar pública municipal em Campinas: o Parque Infantil da Vila Industrial. TCC/Unicamp. Campinas, SP, 1996. 
